\title{
Selenium, Zinc and Probiotics Ameliorate the Effect of High Ambient Temperature: A Review
}

\author{
Zia Ziauddin ${ }^{1}$, Kamal Said Ismail ${ }^{2}$ \\ ${ }^{1}$ Animal Science department, Agriculture Faculty, Said Jamaluddin Afghani University, Kunar Province, Afghanistan. \\ ${ }^{2}$ Veterinary Science Faculty, Shaikh Zayed University, Khost Province, Afghanistan.
}

\begin{abstract}
The exhibition, wellbeing, and prosperity of domesticated animals are firmly affected by environment. Higher encompassing temperature and stickiness are natural stressors that cause weight on animals. Then again, heat pressure is the central point in decreasing animals' creation, propagation and resistance. Minor components like Selenium (Se) and Zinc (Zn) are fundamental for keeping up with wellbeing and resistance and assume a significant part in cancer prevention agent safeguard and invulnerability capacity and they are engaged with development, creation and generation and go about as cofactors of proteins which are vital to the insusceptibility of creature. Besides, probiotics are basically living microorganisms that, when applied in adequate amounts, give the host medical advantages and affect have creatures. Accordingly, the motivation behind this survey was to evaluate that Selenium, Zinc and probiotics further develop Animal wellbeing, cell reinforcement status and safe Function raised under high surrounding temperature.
\end{abstract}

KEYWORDS: High Ambient Temperature, Probiotics, Selenium, Zinc.

\section{INTRODUCTION}

The presentation, wellbeing, and prosperity of animals are emphatically affected by environment. Higher surrounding temperature, higher immediate and aberrant sun oriented radiation and moistness are natural stressors that cause weight on creatures. Among the ecological factors influencing animals, heat pressure is by all accounts one of the most interesting elements that prevent creature creation in many area of the planet. The exhibition, wellbeing, and prosperity of domesticated animals are firmly affected by environment. Higher encompassing temperature, higher immediate and circuitous sun powered radiation and moistness are ecological stressors that cause weight on creatures. Among the natural factors influencing animals, heat pressure is by all accounts one of the most captivating elements that frustrate creature creation in many region of the planet. Notwithstanding the arising information on creatures' reaction to the climate, overseeing domesticated animals to diminish environment sway stays a test. In this way, domesticated animals' scientists need to put forth extraordinary attempts to manage the effects of natural strain on animals' creation. As well as guaranteeing the jobs of poor and peripheral ranchers, decreasing pressure can likewise work on the economy of the whole animals industry. It is hence essential to comprehend the effect of ecological weights on animals' creation and generation. These endeavors might assist with recognizing suitable objectives for creating proper relief techniques. Warm pressure impacts on domesticated animals are of multifactorial nature. It straightforwardly modifies and disables the cell capacities in different tissues of the body and the reallocation of blood stream, as well as the decrease in food admission, which eventually brings about diminished creation execution. Regenerative elements of domesticated animals are especially helpless against environmental change; it has been laid out that enormous ruminants are more inclined to warm pressure contrasted and little ruminants [1]. Also, heat pressure is the significant reason for fruitlessness and conceptive failure in domesticated animals, bringing about significant financial misfortunes as well as decreases the charisma, fruitfulness and undeveloped endurance in animals and favors the event of sicknesses in children with diminished insusceptibility. Moreover, heat pressure influences the fruitfulness and regenerative execution of domesticated animals species through compromising the elements of the conceptive lot, disturbing the hormonal equilibrium, diminishing the oocyte quality, and in this manner diminishing incipient organism advancement and endurance [2-4]. In the tropical and subtropical regions, during the hot season, both the low quality of oocytes and undeveloped organisms brings about diminished origination rate and consequently with more days' open bringing about enormous financial misfortunes to the dairy business [5]. The high surrounding temperature and relative mugginess straightforwardly influence multiplication by adjusting or weakening different tissues or organs of the conceptive arrangement of creature [6]. The limit level of temperature mugginess 


\title{
International Journal of Current Science Research and Review
}

\author{
ISSN: 2581-8341
}

\section{Volume 05 Issue 02 February 2022}

DOI: 10.47191/ijesrr/V5-i2-25, Impact Factor: 5.825

IJCSRR@ 2022

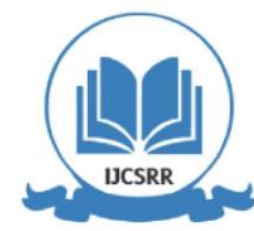

www.ijcsrr.org

record (THI) for the superior exhibition as far as milk yield and proliferation is around THI 72 in tropical and subtropical environments. In any case, ongoing examinations on THI in calm environment underlined that the THI lower than 68 is appropriate for cows execution and government assistance [7].

Minor components, however expected in little amounts (under $100 \mathrm{mg} / \mathrm{kg}$ dry matter), and are fundamental for keeping up with wellbeing and invulnerability. They are associated with development, creation and proliferation and go about as cofactors of catalysts which are critical to the insusceptibility of creature. Superoxide dismutase, glutathione reductase, glutathione peroxidase, thioredoxin reductase, ceruloplasmin and catalase are significant proteins that have minor components as cofactors and go about as cell reinforcements and forestall oxidative pressure by killing oxidants created under various burdens. Plus, minor components add to general health of animal subsequently improving infection opposition as well as significant for appropriate working of various catalysts and proteins which are associated with numerous physiological, biochemical and metabolic cycles that add to development and creation. Generally speaking, minor components work on resistant ability and useful execution [8]. Probiotics have been as of late characterized as live microorganisms which when directed in sufficient sums present a medical advantage on the host and a decent probiotics ought to be non-pathogenic, non-poisonous and fit for applying helpful impact on the host creature. Besides, probiotic items might contain at least one chose microbial strains of microscopic organisms with exceptional quality of biochemical exercises in the body to upgrade general body execution of creatures and human. Review have likewise shown that probiotics might contain organism and protozoa [9] and they have been uncovered to advance development, further develop productivity of feed use, shield have from digestive contamination and invigorate insusceptible reactions in livestock [9].Therefor, the this audit has been depicted the "Selenium, Zinc and Probiotics Ameliorate the Effect of high Ambient Temperature" in Animals. At long last, the motivation behind this survey was to portray the likely impacts of Probiotics, Selenium, and Zinc in heat pressure condition.

\section{SELENIUM AND THE IMPACTS OF ITS LACK IN ANIMAL HEALTH}

Selenium is a significant minor element, its need has an adverse consequence on the strength of people and creatures and its inadequacy has an extensive monetary impact, like a decrease in fruitfulness, placental maintenance, mastitis, and metritis. In steers, selenium uses has different activities connected with creature creation, ripeness and infection counteraction [10-12]. At the point when selenium was added, the expansion in fruitfulness was ascribed to a reduction in undeveloped organism passing during the main month of pregnancy. In insusceptible framework, selenium assumes a part in the development and action of aide $\mathrm{T}$ cells, cytotoxic T cells and regular Killer (NK) cells [13]. Selenium inadequacy will prompt perinatal sicknesses, which will change the milk nature of dairy cows [14], and its assumes a part in keeping cell digestion from creating hydrogen peroxide amassing [15]. This natural capacity is acknowledged by Selenoproteins, for example, glutathione peroxidase family (GPX), iodothyronine deiodinase and thioredoxin reductase, in which selenium is the primary part [16]. Besides, the cancer prevention agent impacts of Se were recommended to be intervened through the glutathione peroxidase (GSH-Px) catalysts, which convert possibly harming lipid hydroperoxides and hydrogen peroxide to less poisonous items and assume a special part in safeguarding cells against free extremist incited oxidative pressure. Really more than 30 selenoenzymes have been portrayed and an order cycle for articulation in the creature has been laid out. White muscle sickness (WMD) was the principal perceived condition related with Se lack. WMD causes new conceived mortality, particularly in ruminants, and impeded creation condition in developing and grown-up animal. Selenium is basic to thyroid chemical union and it is additionally vital for changing over T4 (thyroxin idle structure) to T3 (dynamic structure). A decent invulnerable reaction requires Se as well. Selenium status in soil, plants and creature blood and tissue can be utilized in the finding of Se lack. Different types of Se supplements are accessible, however many elements influence their action and viability, for example, its compound structure and creature's wellbeing and creation condition. The connections between embryo Se digestion and pregnant dam Se status are basic for efficiency and need further exploration [17].

\section{THE SIGNIFICANT OF SELENIUM IN BIOLOGICAL SYSTEM}

Plants are the passage for the creatures' selenium that assimilate inorganic components from the dirt and converts to natural components structure. As a general rule, soil accessibility of the selenium is differs starting with one locale then onto the next district and low selenium has been distinguished in volcanoes and "acidic soil" regions, for example, southeastern United States [18, 19]. Without selenium consumption by plants is enduring by the presence of different components like sulfur ( $\mathrm{S}$ ), iron (Fe) and aluminum (Al) [20]. Subsequently, these regions have recorded illnesses related with the absence of selenium in creatures and people, and 


\section{International Journal of Current Science Research and Review}

ISSN: 2581-8341

Volume 05 Issue 02 February 2022

DOI: 10.47191/ijcsrr/V5-i2-25, Impact Factor: 5.825

food is chiefly delivered locally. In plants, selenium is changed over into natural structures, for instance amino corrosive selenomethionine and methylated low sub-atomic weight selenium compounds, which are the fundamental selenium compounds in grains, beans and soybeans, while they are likewise utilized as antecedents for Sec combination in significant creatures, and other selenium metabolites can likewise be utilized in this interaction [21]. In natural frameworks, Sec is viewed as a recreation of Cys, which is the most dynamic organically type of selenium [19].

\section{THE SIGNIFICANCE OF ZINC IN BIOLOGICAL SYSTEMS}

Zinc is a progress metal that has demonstrated to be a fundamental supplement for typical development and wellbeing in numerous creatures, while zinc is a significant piece of numerous metal compounds [22], that seem to assume a functioning part in numerous physiological cycles including insusceptibility, development, multiplication and nourishing digestion. What's more, zinc lack in creatures was first portrayed in 1980, described by clinical manifestations like hindering, decreased feed admission and skin injuries. 1980 [23]. For a long time, the creature diet has been enhanced with zinc to forestall zinc inadequacy and work on creature development and creation, and its real eating routine is generally usually utilized as inorganic zinc sources, for example, zinc sulfate and zinc oxide [24]. As of late, the issue of natural zinc source has drawn in much consideration. The utilization of natural minor elements in apportions to supplant customary inorganic mineral sources has become normal because of escalated activities and expanded animals execution prerequisites, and natural minerals are attempted to be organically more open to creatures than inorganic minerals, yet the specific component of activity of natural minerals stays indistinct [25]. Studies have shown that natural mineral taking care of can work on creature development and insusceptible reaction. Be that as it may, there has been further examination on the assimilation and digestion of natural minerals in creatures. The idea of natural minerals was perceived quite a while back [26, 27]. Zinc is likewise significant for balancing out the construction of numerous proteins and structures part of other catalyst dynamic destinations. It is a fundamental component in excess of 200 compounds, including carboxypeptidases, RNA polymerase III, liquor dehydrogenase, and connective tissue, albeit the specific job of zinc in the development of connective tissue is as yet unclear [22, $28]$.

\section{ANTIOXIDANT PROPERTIES OF ZINC}

Antioxidant are substances or atoms that repress the oxidation of another particle. Despite the fact that zinc isn't completely incorporated into the meaning of cell reinforcements, it has been displayed to have comparative properties commonly by applying backhanded consequences for oxidants. As a cell reinforcement, zinc has both intense and ongoing impacts. In the midst of constant hardship of zinc, a creature can turn out to be more powerless to injury by oxidative pressure [29]. The intense impacts of zinc incorporate adjustment of sulfhydryl's by safeguarding them from oxidation as well as lessening the development of $\mathrm{OH}$ from $\mathrm{H} 2 \mathrm{O} 2$ and superoxide. This is significant on the grounds that few examinations have shown that the metal-catalyzed development of $\mathrm{OH}$ can animate cycles that are destructive to cells [29]. Zinc has additionally been displayed to decrease impacts of ischemic harm and hinder the oxidation of proteins. This is likewise a co-factor in the antioxidative catalyst copper-zinc superoxide dismutase. These impacts have been demonstrated to be advantageous, yet the essential system of how zinc produces cell reinforcement properties stays obscure [30].

\section{PROBIOTICS}

In escalated creature production system, the healthful prerequisites of animals can be met through supplementation of the restricting supplements in concentrated structure, so they can deliver huge amounts of items quickly. In any case, the utilization of feedstuffs that are quickly aged in the rumen can make conditions in the rumen that are problematic for the fibrolytic microorganisms, in this way disabling fiber processing. Besides, wholesome nature of a feed isn't just impacted by supplement content yet in addition by numerous different viewpoints, for example, cleanliness, content of against nourishing elements, edibility, tastefulness and impact on gastrointestinal wellbeing. Consequently, the utilization of feed added substances has been a significant piece of making this progress [31]. Feed added substances are materials that are utilized to upgrade the adequacy of supplements and apply their impacts in the stomach or on the stomach divider cells to the creature. There are various feed added substances that are utilized in creature feeds, for example, anti-microbials, probiotics, oligosaccharides, proteins and natural acids which can work on the generally speaking physiological presentation of creatures [32]. 


\section{International Journal of Current Science Research and Review}

ISSN: 2581-8341

Volume 05 Issue 02 February 2022

DOI: 10.47191/ijcsrr/V5-i2-25, Impact Factor: 5.825

IJCSRR@ 2022

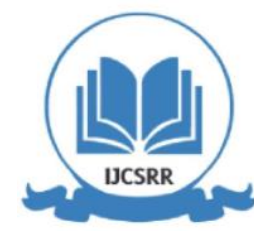

wWw.ijcsrr.org

Probiotics are characterized as live microorganisms which can give a medical advantage for the host when directed in proper and ordinary amounts. The joint Food and Agriculture Organization of the United Nations (FAO) and World Health Organization (WHO) Working gathering additionally characterized probiotics as "live microorganisms which when regulated in sufficient sums give a medical advantage on the host" (FAO/WHO, 2001). Probiotics are progressively utilized in business creature creation activities to favorably modify gastrointestinal verdure, subsequently working on creature wellbeing and usefulness [33]. The utilization probiotics as feed enhancements to accomplish better creature wellbeing, government assistance and efficiency through control of the stomach miniature biota biological system has acquired impressive consideration over the most recent thirty years [34].

\section{QUALITIES OF GOOD PROBIOTICS}

Great probiotics are fit for applying an advantageous impact on the host creature, non-pathogenic and non-poisonous, present as suitable cells, ideally en masse, equipped for getting by and utilizing in the stomach climate and steady and fit for staying reasonable for periods under capacity and field conditions [35].

\section{ROLE OF PROBIOTICS FEED ADDITIVE IN RUMINANT PRODUCTIVITY AND HEALTH}

The rumen has a complex microbial biology, where polysaccharides and protein ingested by the host are corrupted by rumen miniature creatures, bringing about the blend of SCFAs and microbial protein, which are utilized by the host as energy and protein source [36]. There is expanding worldwide interest in controlling the rumen biological system to build the proficiency of the ruminal maturation cycles to work on creature efficiency and diminish undesirable results, for example, methane [37].

Yeast (S. cerevisiae) is a generally involved probiotic in ruminants influencing principally the microbial populace elements in the rumen and the breakdown of supplements. Lactic corrosive delivering microscopic organisms are one more significant gathering of probiotics [38].

Aside from the utilization of probiotics in figured out creature feed, gainful microorganisms utilized as silage inoculants may likewise have a probiotic impact in the rumen. In any case, this reaction relies upon the endurance of the silage inoculant in the silage as the $\mathrm{pH}$ drops [39].

\section{CONCLUSION}

Minor components like Selenium (Se) and Zinc (Zn) are fundamental for keeping up with wellbeing and insusceptibility and assume a significant part in cell reinforcement protection and invulnerability capacity and they are associated with development, creation and generation and go about as cofactors of compounds which are essential to the resistance of creature. Also, probiotics are basically living microorganisms that, when applied in adequate amounts, give the host medical advantages and effetely affect have creatures.

\section{REFERENCE}

1. Upadhyay, R.C., et al., Impact of climate change on reproductive functions of Murrah buffaloes. Journal of Animal and Plant Sciences, 2012. 22: p. 234-236.

2. Wolfenson, D., Z. Roth, and R. Meidan, Impaired reproduction in heat-stressed cattle: basic and applied aspects. Animal Reproduction Science, 2000. 60-61: p. 535-547.

3. Gendelman, M. and Z. Roth, Seasonal Effect on Germinal Vesicle-Stage Bovine Oocytes Is Further Expressed by Alterations in Transcript Levels in the Developing Embryos Associated with Reduced Developmental Competence1. Biology of Reproduction, 2012. 86(1).

4. Gendelman, M. and Z. Roth, In vivo vs. in vitro models for studying the effects of elevated temperature on the GV-stage oocyte, subsequent developmental competence and gene expression. Animal Reproduction Science, 2012. 134(3): p. 125134.

5. Collier, R.J., G.E. Dahl, and M.J. VanBaale, Major Advances Associated with Environmental Effects on Dairy Cattle. Journal of Dairy Science, 2006. 89(4): p. 1244-1253.

6. Dash, S., et al., Effect of heat stress on reproductive performances of dairy cattle and buffaloes: A review. Veterinary world, 2016. 9(3): p. 235-244. 


\section{International Journal of Current Science Research and Review}

ISSN: 2581-8341

Volume 05 Issue 02 February 2022

DOI: 10.47191/ijesrr/V5-i2-25, Impact Factor: 5.825

IJCSRR@ 2022

www.ijesrr.org

7. Gauly, M., et al., Future consequences and challenges for dairy cow production systems arising from climate change in Central Europe - A review. Animal : an international journal of animal bioscience, 2012. 7: p. 1-17.

8. Yatoo, D.M., et al., Role of trace elements in animals: A review. Veterinary World, 2013. 6: p. 963-967.

9. Gudeta, D. and Guder, Role of Probiotics in Animal Productivity and Health: A Review. 2019.

10. Spears, J.W. and W.P. Weiss, Role of antioxidants and trace elements in health and immunity of transition dairy cows. The Veterinary Journal, 2008. 176(1): p. 70-76.

11. Hefnawy, A. and J. Tortora, The importance of selenium and the effects of its deficiency in animal health. Small Ruminant Research - SMALL RUMINANT RES, 2010. 89: p. 185-192.

12. Sordillo, L.M., Selenium-dependent regulation of oxidative stress and immunity in periparturient dairy cattle. Veterinary medicine international, 2013. 2013: p. 154045-154045.

13. Petrie, H.T., et al., Selenium and the immune response: 2. Enhancement of murine cytotoxic T-lymphocyte and natural killer cell cytotoxicity in vivo. J Leukoc Biol, 1989. 45(3): p. 215-20.

14. Ran, L., et al., Effects of selenium form on blood and milk selenium concentrations, milk component and milk fatty acid composition in dairy cows. J Sci Food Agric, 2010. 90(13): p. 2214-9.

15. Sordillo, L.M., Nutritional strategies to optimize dairy cattle immunity1. Journal of Dairy Science, 2016. 99(6): p. 49674982.

16. Forman, H.J., H. Zhang, and A. Rinna, Glutathione: overview of its protective roles, measurement, and biosynthesis. Molecular aspects of medicine, 2009. 30(1-2): p. 1-12.

17. Mehdi, Y., et al., Selenium in the Environment, Metabolism and Involvement in Body Functions. Molecules (Basel, Switzerland), 2013. 18: p. 3292-311.

18. Mahmoud, K.Z. and F.W. Edens, Influence of selenium sources on age-related and mild heat stress-related changes of blood and liver glutathione redox cycle in broiler chickens (Gallus domesticus). Comparative Biochemistry and Physiology Part B: Biochemistry and Molecular Biology, 2003. 136(4): p. 921-934.

19. Rezende, V.B., et al., Correlations among antiangiogenic factors and trace elements in hypertensive disorders of pregnancy. J Trace Elem Med Biol, 2015. 29: p. 130-5.

20. Terry, N., et al., SELENIUM IN HIGHER PLANTS. Annu Rev Plant Physiol Plant Mol Biol, 2000. 51: p. 401-432.

21. Whanger, P.D., Selenocompounds in plants and animals and their biological significance. J Am Coll Nutr, 2002. 21(3): p. 223-32.

22. Riordan, J.F., Biochemistry of Zinc. Medical Clinics of North America, 1976. 60(4): p. 661-674.

23. TODD, W.R., C.A. ELVEHJEM, and E.B.J.N.R.V. HART, ZINC IN THE NUTRITION OF THE RAT. 1980(4).

24. Wedekind, K.J. and D.H. Baker, Zinc bioavailability in feed-grade sources of zinc. Journal of Animal Science, 1990. 68(3): p. 684-689.

25. Cortinhas, C., et al., Organic and inorganic sources of zinc, copper and selenium in diets for dairy cows: Intake, blood metabolic profile, milk yield and composition. Revista Brasileira de Zootecnia, 2012. 41: p. 1477-1483.

26. López-Alonso, M., Trace minerals and livestock: not too much not too little. ISRN veterinary science, 2012. 2012: p. 704825-704825.

27. Cufadar, Y., et al., Effects of Dietary Different Levels of Nano, Organic and Inorganic Zinc Sources on Performance, Eggshell Quality, Bone Mechanical Parameters and Mineral Contents of the Tibia, Liver, Serum and Excreta in Laying Hens. Biological Trace Element Research, 2019.

28. MacDonald, R.S., The Role of Zinc in Growth and Cell Proliferation. The Journal of Nutrition, 2000. 130(5): p. 1500S$1508 \mathrm{~S}$

29. Powell, S.R., The Antioxidant Properties of Zinc. The Journal of Nutrition, 2000. 130(5): p. 1447S-1454S.

30. Martin, K.M., The effects of zinc supplementation from two sources on egg quality and bone health in laying hens. 2016.

31. Smith, J., et al., Beyond milk, meat, and eggs: Role of livestock in food and nutrition security. 2013. 3(1): p. 6-13.

32. Sharma Bajagai, Y., et al., Probiotics in animal nutrition: production, impacts and regulation. 2016.

33. Morelli, L. and L.J.J.o.c.g. Capurso, FAO/WHO guidelines on probiotics: 10 years later. 2012. 46: p. S1-S2. 


\section{International Journal of Current Science Research and Review}

ISSN: 2581-8341

Volume 05 Issue 02 February 2022

DOI: 10.47191/ijcsrr/V5-i2-25, Impact Factor: 5.825

IJCSRR@ 2022

34. Giannenas, I., et al., Assessment of dietary supplementation with probiotics on performance, intestinal morphology and microflora of chickens infected with Eimeria tenella. 2012. 188(1-2): p. 31-40.

35. Islam, F. and N.J.B.r.n. Roy, Screening, purification and characterization of cellulase from cellulase producing bacteria in molasses. 2018. 11(1): p. 445.

36. Boyd, J., J. West, and J. Bernard, Effects of the addition of direct-fed microbials and glycerol to the diet of lactating dairy cows on milk yield and apparent efficiency of yield. Journal of dairy science, 2011. 94: p. 4616-22.

37. Uyeno, Y., S. Shigemori, and T. Shimosato, Effect of Probiotics/Prebiotics on Cattle Health and Productivity. Microbes and environments, 2015. 30(2): p. 126-132.

38. Hristov, A.N., et al., Effect of Saccharomyces cerevisiae fermentation product on ruminal fermentation and nutrient utilization in dairy cows. Journal of Dairy Science, 2010. 93(2): p. 682-692.

39. Ghazanfar, S., et al., Effects of dietary supplementation of yeast (Saccharomyces cerevisiae) culture on growth performance, blood parameters, nutrient digestibility and fecal flora of dairy heifers. JAPS, Journal of Animal and Plant Sciences, 2015. 25(1): p. 53-59.

Cite this Article: Zia Ziauddin, Kamal Said Ismail (2022). Selenium, Zinc and Probiotics Ameliorate the Effect of High Ambient Temperature: A Review. International Journal of Current Science Research and Review, 5(2), 520-525 